Artículo

\title{
El nivel de vida en un país naciente y diverso. Salarios, precios de alimentos y cobertura de una canasta de subsistencia en las 14 provincias de Argentina, 1875
}

\author{
Julio Djenderedjian* $\mathbb{D}$ \\ Universidad de Buenos Aires. Instituto Ravignani. Consejo Nacional de Investigaciones Científicas y Técnicas
}

\section{INFORMACIÓN DEL ARTÍCULO}

\section{Historia del artículo:}

Recibido el 14 de abril de 2018

Aceptado el 9 de octubre de 2018

On-line el 4 de febrero de 2020

\section{Códigos JEL:}

N36

D31

P46

Palabras clave:

Niveles de vida

Argentina

Siglo XIX

Canastas de subsistencia

\section{JEL classification:}

N36

D31

P46

\section{Keywords:}

Standards of living

Argentina

19th.Century

Bare Bones Baskets

\section{R E S U M E N}

Los estudios sobre nivel de vida para épocas preestadísticas han registrado considerables avances en las últimas décadas, pero las metodologías empleadas para la comparación internacional a menudo aún adolecen de problemas. Aquí analizamos la cobertura de una canasta básica de subsistencia en diferentes puntos de Argentina para 1875, utilizando una importante fuente no trabajada, el informe del Comisario General de Inmigración, que ofrece datos de salarios y costo de alimentos para ciudades en todas las provincias de entonces. Los resultados muestran: a) niveles de vida en general relativamente altos en comparación con varias ciudades europeas; pero b) una gran diversidad entre las regiones que conformaban el país, consistente con áreas internas de expulsión y atracción de migrantes. Se deduce que es necesario conocer las características de los grupos familiares y la extensión de la relación salarial para obtener resultados realistas, no solo en la comparación internacional, sino incluso entre las distintas regiones de un mismo país.

C 2018 Asociación Española de Historia Económica.

\section{Living standards in an emerging and diverse country. Salaries, costs of food, and a Bare Bone Basket coverage in the 14 provinces of Argentina, 1875}

\section{A B S T R A C T}

Research on living standards of the past have experienced great improvements in the last decades. But, when dealing with international comparison, methodological issues arise. Here we seek to find the coverage of a basic "Bare Bone Basket" in different parts of Argentina for the year 1875, through a very interesting source: the report of the Comisario General de Inmigración, offering data on salaries and food prices for cities in the 14 Argentine provinces of that time. The results show: a) a relatively high standard of living when compared with several European cities; but also b) strong diversity inside the country, consistent with internal areas of expulsion and attraction of migrants. Concluding remarks stress the need of a deeper knowledge of local family group structure, and the extent of wage system, in order to assess realistic comparisons, both international or between different regions in a single country.

\footnotetext{
Autor para correspondencia.

Correo electrónico: juliodjend@yahoo.com.ar (Julio Djenderedjian)
} 


\section{Introducción}

Los estudios sobre nivel de vida para épocas preestadísticas han registrado considerables avances en las últimas décadas, particularmente en función de estrategias ad hoc, diseñadas para sortear la falta de los indicadores usuales en la actualidad para mediciones de ese tipo, y orientadas además a resolver problemas de magnitud mediante la comparación internacional $^{1}$. Esas estrategias, sin embargo, quizá porque son relativamente sencillas, han proliferado sin que siempre se haya tenido en cuenta que los datos de una ciudad durante unos pocos años rara vez dan cuenta de la compleja evolución y gran diversidad de situaciones de un territorio de miles de kilómetros cuadrados, sobre todo en épocas en que la integración de los mercados de bienes y de factores productivos estaba aún en ciernes ${ }^{2}$.

En Argentina los avances han sido notables. Entre ellos se incluyen varios intentos por construir indicadores más complejos y sólidos, el estudio de diversas alternativas y el aprovechamiento de las a menudo parcas e incompletas fuentes disponibles ${ }^{3}$. Pero no contamos aún con una visión de conjunto provista por fuentes relativamente homogéneas para antes del siglo xx. Los estudios existentes han aprovechado los trabajos realizados para la ciudad de Buenos Aires acerca del final del siglo XIX (Cortés Conde, 1979; Williamson, 1995), pero lo que ocurría en el resto de Argentina es aún una incógnita. Contamos, sí, con varios estudios regionales; sin embargo, los mismos tratan épocas distintas y no cubren la totalidad del país ${ }^{4}$. En ese sentido, aquí proponemos un análisis efectuado a partir de una sola fuente, bastante homogénea en tanto surgió de los datos hasta cierto punto normalizados y publicados por una sola oficina pública. Se trata del informe anual del comisario general de Inmigración, el primero de los publica-

\footnotetext{
${ }_{1}$ Allen (2001). El debate en el que se generaron esos estudios buscaba explorar las causas del "retraso» relativo de algunas naciones o regiones, vis à vis las del hemisferio norte, en los tiempos en que nacía el mundo moderno (siglos XVIII-XIX). Entre otros, era patente el «retraso» de la América hispánica, que en esos siglos había pasado de ser una de las regiones más ricas y centrales del globo, a apenas conformarse en él con un lugar marginal (Haber, 1997). La posterior multiplicación de trabajos intentó, con dispar fortuna, efectuar comparaciones internacionales lo más amplias posibles.

${ }^{2}$ La propuesta desarrollada por Allen y otros puede ser útil para analizar economías relativamente integradas aun en épocas protoindustriales, pero no necesariamente lo es para otras que no lo estaban. Deben por tanto conocerse profundamente las características de cada economía antes de encarar comparaciones o extrapolaciones a partir de los datos de una sola ciudad.

${ }^{3}$ Por ejemplo, Salvatore (2007), un pionero en el desarrollo de los estudios antropométricos en Argentina. Buscando resolver los problemas de los indicadores à la Allen, algunos autores incorporaron varias estrategias alternativas, como la distribución funcional del ingreso de Gelman y Santilli (2015). Un reciente dosier, coordinado y prologado por Santilli (2016), es una aproximación muy útil a los avances, problemas y potencialidades de los estudios sobre nivel de vida en el espacio rioplatense.

${ }^{4}$ Por ejemplo, los de Campi (2004) sobre Tucumán, o Bragoni y Olguín (2016) para Mendoza, ambos con información de finales del siglo xIx. El censo nacional de 1895, que incluye datos de actividades económicas, y del que constan las fichas manuscritas originales con los datos nominales individuales de los censados, podría dar seguramente una imagen general muy detallada y útil, pero procesar los muchos cientos de miles de datos que contiene y lograr solucionar las múltiples lagunas que no cubren habrá de dar trabajo durante muchos años a un gran equipo de investigación. Para inicios del siglo xx contamos con el estudio de Correa Deza y Nicolini (2014), que compara distintas ciudades del país.
}

dos, cuyos datos corresponden a 1875, y que es el único que conocemos en el que se llevó a cabo y publicó una encuesta nacional de esa envergadura y características ${ }^{5}$. Esos datos, recogidos en informes particulares de cada localidad, fueron remitidos a la oficina central desde las existentes en cada una de las catorce provincias, y respondían a una serie de preguntas relacionadas con los salarios corrientes en ellas, el costo de los alimentos básicos, los precios de la tierra y del ganado, así como las principales actividades rurales y urbanas. Se buscaba de ese modo crear una obra útil para orientar a la creciente ola de inmigrantes extranjeros, a fin de que se dirigiera a las regiones, ciudades y áreas en las cuales había mejores posibilidades de progreso o donde la escasez de trabajadores fuera mayor o en las que se requirieran determinadas especialidades. Por ello, también se incluyó un estudio sumario de las profesiones más y menos demandadas, así como una serie de datos relativos a los extranjeros ya instalados, sus iniciativas, sus problemas, sus progresos y sus necesidades. Por tratarse de un momento previo a la plena conformación de un mercado nacional, cuando aún era muy incipiente la comunicación moderna y los mercados de bienes estaban provistos fundamentalmente por sus propias regiones, resulta un útil observatorio de la heterogeneidad de situaciones, en particular evidentes no solo en la dispersión de los valores, sino también en la gran diversidad de ocupaciones, en muchos sitios pautadas mayormente por los imperativos de una economía rural y tradicional que contrastaba, sin embargo, con el dinamismo de las áreas litorales volcadas hacia la economía atlántica.

Seguidamente daremos algunos datos sobre el contexto en el cual surge esta fuente y la naturaleza de su información; hemos buscado formular ratios de bienestar utilizando las categorías más bajas de asalariados (a jornal y por mes), relacionando sus ingresos con el costo de una canasta básica alimentaria de 1941 calorías, aproximadamente en los términos de Allen (2001), con el fin de obtener indicadores susceptibles de mostrarnos la diversidad de situaciones en el interior del país, su diferencia con respecto a Buenos Aires (de lejos la mejor estudiada), y ponderarlos para elaborar uno que represente algo más fehacientemente al país entero que su opulenta capital.

Una aclaración: se ha señalado repetidas veces la irrealidad de ciertos supuestos básicos utilizados en construcción de canastas y salarios reales; en particular, el tamaño de la unidad familiar o la presunción de que un salario es representativo del ingreso de una familia ${ }^{6}$. Esos problemas surgen fundamentalmente de una actitud etnocéntrica: como lo señaló hace ya varios años Roger Schofield (1989, pp. 280-285), la estructura familiar difiere sustancialmente, no ya solo entre lejanas realidades como China e Inglaterra, sino también entre la de esta última y otros cercanos países europeos, o incluso en el interior mismo de cada país. También difiere el rol del salario como ingreso en economías que, solo por mencionar un rasgo, tienen o no grandes masas de esclavos o población bajo diferentes tipos de servidumbre o amplio cuentapropismo ${ }^{7}$. Para salvar

\footnotetext{
${ }^{5}$ La fuente se encuentra en Argentina: Comisaría General de Inmigración (1876).

${ }^{6}$ Ver, por ejemplo, Gelman y Santilli (2016); Dobado y García Montero (2014); Djenderedjian y Martirén (2016).

7 Es lo que solía ocurrir con los contingentes de familias indígenas reclutados para el laboreo del azúcar u otros productos en distintos países
} de América Latina a finales del siglo xIx. 
esos inconvenientes aquí apelaremos a dos estrategias: la primera, considerar el tamaño promedio de la familia en cada una de las localidades que estudiaremos y obtener, para el cálculo general, un promedio; la segunda, estipular un ingreso familiar proporcionado con las características del contrato en esos años (que incluía usualmente los alimentos del trabajador), el tamaño de la familia y su composición y la posibilidad de obtener ingresos por parte de más de un miembro adulto de ella.

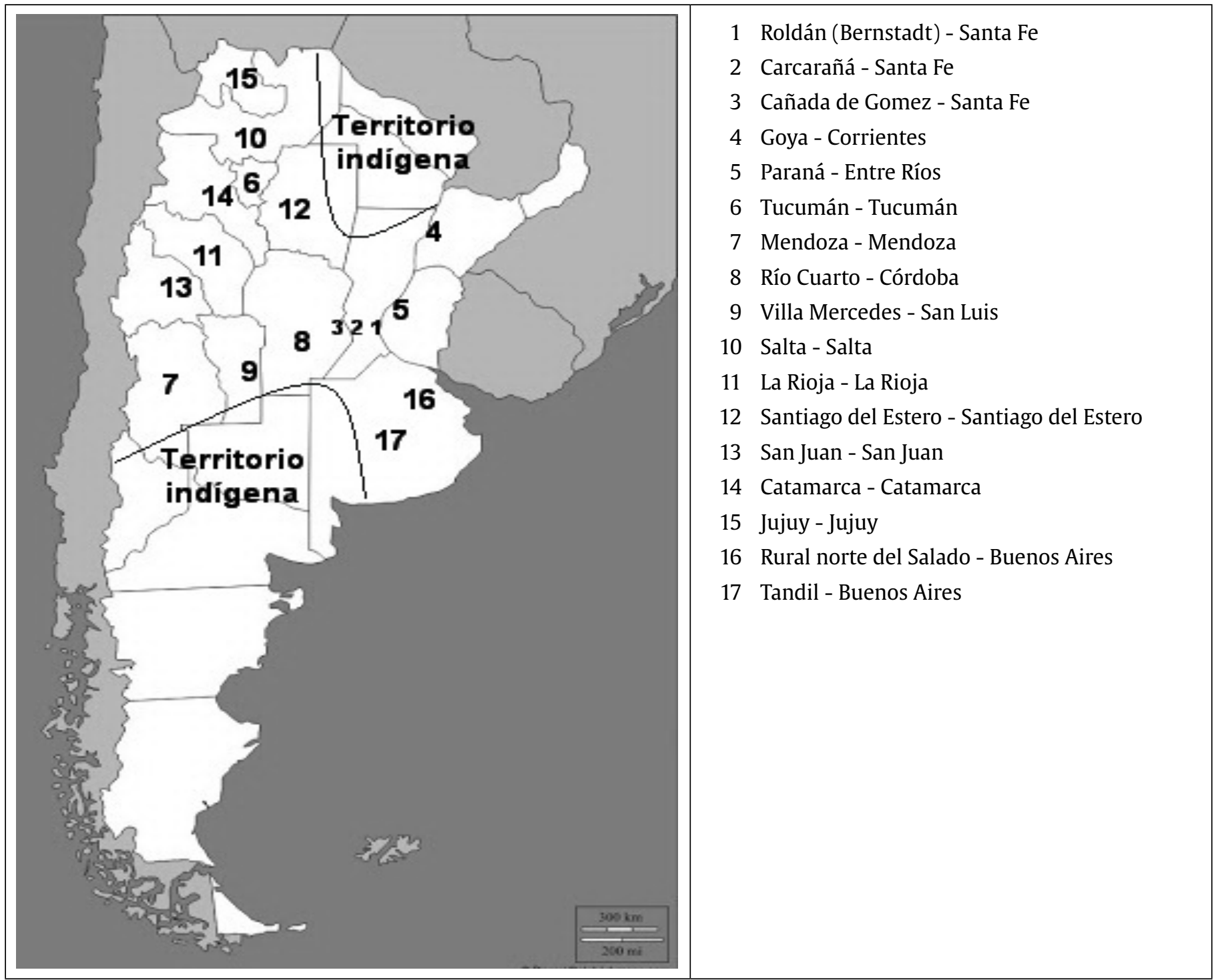

Mapa 1. Posición de las localidades analizadas.

Fuente: elaboración propia a partir de Napp (1876).

\section{La fuente y su contexto}

Durante el gobierno del presidente Nicolás Avellaneda (1874 a 1880), la Argentina logró por fin completar su conformación política, cerrando así un largo ciclo de conflictos. Si bien el país como tal existía unificado desde 1862, solo en 1880 el Gobierno nacional alcanzó a dominar las últimas resistencias autonómicas. La sangre estaba aún fresca; en 1870 había terminado la más dura de las muchas guerras que habían afectado el tormentoso curso de su historia; los gobiernos provinciales eran todavía tan poco estables como para que uno de ellos pudiera ser derrocado por una dama y sus amigas luego de una reunión social; las asonadas y "revoluciones» eran moneda corriente, y en las fronteras del norte y del sur ofrecían sólida resistencia belicosas tribus indígenas. Hacia 1875 ese país aún se encon- traba luchando por asentar una economía nacional; apenas cinco años antes las líneas férreas habían logrado conectar a las dos ciudades más importantes del interior (Rosario y Córdoba), pero faltaba mucho para que alcanzaran los demás núcleos urbanos principales y los límites del territorio. Las incipientes líneas que existían tenían solo un trazado y recorrido provincial; incluso con diferentes características técnicas, que habrían posteriormente de dificultar su interconexión ${ }^{8}$. Si bien desde hacía ya dos décadas prosperaban varios emprendimientos de colonización agrícola con inmigrantes extranjeros, y estos últimos formaban parte cada vez más consistente de la población,

\footnotetext{
${ }^{8}$ Un buen panorama general del país en esos años en Gelman (2011).
} 
de todos modos algunos diplomáticos se creían en el deber de señalar a sus compatriotas los riesgos y las dificultades que traía aparejada la vida en el país, y ciertos brotes aislados de xenofobia hacían cundir la alarma, siendo acerbamente reproducidos por los medios de prensa ${ }^{9}$. El esquema económico todavía se asentaba, en las regiones litorales, sobre la ganadería extensiva, mayormente ovina en Buenos Aires y vacuna en Entre Ríos; Santa Fe se debatía tratando de construir un perfil productivo más complejo impulsando la agricultura, y los productores de Córdoba y de otras provincias del interior buscaban, con un angustiosamente corto haz de bienes exportables, participar del comercio exterior a fin de sortear la pobreza y magra dimensión demográfica de los mercados locales. No existía una moneda unificada, ni siquiera una moneda nacional. El Banco Nacional se crearía en 1873 y sus billetes encontrarán férrea competencia por parte de los más asentados de la provincia de Buenos Aires, al punto de hacerlos fracasar. Mientras tanto, el resto del país se manejaba con piezas de plata acuñadas mayormente en Bolivia, y de valores y contenido intrínseco muy disímil, rechazadas en general en los países limítrofes. Replicando la anarquía, algunas contabilidades oficiales y privadas llevaban sus libros en pesos fuertes, otras lo hacían en pesos bolivianos y Buenos Aires, en fin, en su propio papel moneda, cuya convertibilidad, ensayada desde 1867 luego de casi medio siglo de violentas fluctuaciones del dinero fiat, habría muy pronto de derrumbarse. Esa caótica situación continuaría aun hasta mediados de la década de 1880, en el que el Gobierno nacional lograría imponer su papel moneda en casi todo el territorio.

Ese país en ciernes estaba sin embargo dándose algunas oficinas específicas para lidiar con tan diversos problemas. Una de las áreas que recibió gran atención durante esos años fue la relativa al manejo de las crecientes oleadas de inmigrantes que arribaban al país. Al vincular exitosamente participación privada y gubernamental en diversos emprendimientos desde hacía un par de décadas, la sinergia generada en torno a ello fue haciéndose cada vez más eficaz, y fue sin duda uno de los aspectos de las políticas públicas que más atención recibió. Las instituciones destinadas a la atención y control del flujo de inmigrantes fueron así organizándose y expandiéndose. Desde 1869 existía una Comisión Central de Inmigración que, aunque de creación gubernamental, estaba compuesta por personajes prestigiosos del sector privado. La misma fue estableciendo comisiones en cada capital de provincia y aun en localidades menores. Estas comisiones estaban usualmente compuestas por cinco miembros activos y dos suplentes, y todos los cargos eran honorarios. Entre sus tareas, de índole eminentemente práctica, se incluía, por ejemplo, organizar albergues para recibir a los inmigrantes, centralizar y ordenar la información referente a las solicitudes de trabajadores, traducir documentación, solicitar concesiones de tierras con franquicias para la radicación de productores en ellas, y recopilar y difundir estadísticas, además de publicar memorias detalladas sobre cada territorio ${ }^{10}$. Esta función de

\footnotetext{
${ }^{9}$ El informe de McDonell (1872) es particularmente crítico con las condiciones que debían enfrentar los inmigrantes en Argentina; Santos (2008) relata las peripecias de un raid de asesinatos de extranjeros cometidos por un sujeto desequilibrado, que causó gran sensación. De todos modos se trataba de brotes aislados y problemas puntuales, a menudo potenciados por coyunturas de crisis.

${ }^{10}$ Djenderedjian et al. (2010, pp. 155-164). Incluso resolvían pleitos entre extranjeros y nacionales, y entre los mismos extranjeros, oficiando como consulados ad hoc entre quienes carecían de representación diplomática
}

recopilación de información constituyó un importante factor en la construcción de condiciones más eficaces para la distribución de los inmigrantes, guiados por la expectativa de conseguir las mejores condiciones de contratación o de acceso a la tierra, la producción o el comercio ${ }^{11}$.

Luego de un incidente en los años 1873-74, el Gobierno nacional suprimió la Comisión Central de Inmigración y la reemplazó al año siguiente por un organismo estatal, que pasaría a llamarse Comisaría General de Inmigración y dependería del Poder Ejecutivo, figurando en la nómina del Ministerio del Interior. En 1876, mediante la sanción de una ley específica (n.. 817), el Congreso Nacional articuló de manera orgánica las acciones al respecto. Por medio de la misma, se dio plena entidad y capacidad de supervisión a la antigua Comisaría General al fijar sus deberes y atribuciones ${ }^{12}$. Durante el lapso que transcurre entre la supresión de la Comisión Central y la instalación de la Comisaría, las tareas fueron dirigidas por el antiguo secretario de la primera, Guillermo Wilcken. Este personaje había sido nombrado en 1871 por la Comisión Central para inspeccionar las colonias agrícolas de inmigrantes ya existentes, y presentar un informe sobre ellas ${ }^{13}$. En el mismo es patente la atención obsesiva en torno a los datos prácticos de interés para los posibles colonos: cuáles eran los precios de la tierra, los salarios pagados en épocas normales y de cosecha, los oficios más demandados y los ingresos que se podían obtener ejerciéndolos, el costo de la vida, en particular en alimentos, el precio y las condiciones de acceso a la producción, la calidad, costo y utilidad de las distintas maquinarias empleadas. Wilcken fue un actor de singular importancia en el tema, viajó extensamente para cumplir los encargos oficiales y los datos que recopiló constituyen hoy en día un precioso repositorio de información útil y certera. El informe de 1875 que utilizamos aquí es el primero que realizó la Comisaría General, y acusa la impronta de ese personaje, aunque lleva la firma de su sucesor, Juan Dillon.

El documento consiste en una recopilación de los muy detallados informes remitidos desde cada una de las localidades por los directores de las Comisiones respectivas, además de otros materiales relacionados con los objetivos de la Comisaría. Esos informes formaban parte de las obligaciones establecidas por la ley, y respondían veinte preguntas enviadas por el comisario general, que abarcaban toda o casi toda la información entonces

en la localidad. Los contratos entre trabajadores inmigrantes y empleadores se realizaban en sus oficinas, guardándose en ellas copias de los mismos a fin de garantizar el cumplimiento de las condiciones y la plena comprensión y aceptación de las cláusulas por los interesados. También se valía de intérpretes, y algunos de los miembros de las comisiones eran a menudo políglotas. Hablando de la que funcionaba en Córdoba, el informe afirmaba: «En una palabra: la Oficina de Inmigración [local] es la agencia general para el inmigrante, para la consulta de sus negocios, para las desavenencias entre ellos mismos, y hasta para arreglos de familia. [...]» (Argentina. Comisión Nacional de Inmigración, 1876, p. 189). La importancia de la Comisión se evidencia en que en 1875 consiguió trabajo en las diferentes provincias al $37 \%$ del total de inmigrantes de ultramar que llegaron al país ese año (Alsina, 1900, p. 87).

${ }^{11}$ La Comisión Central, y las regionales, se ocupaban coordinadamente de fundar y mantener asilos para el alojamiento temporario de inmigrantes y de ofrecerles pasajes a los lugares de destino, así como de tramitar las cuestiones relativas al equipaje y aduanas y mantener al día listados de empleos ofrecidos (Ochoa de Eguileor y Valdés, 2000, pp. 81-82 y ss.).

${ }^{12}$ Djenderedjian et al. (2010, pp. 162-164). Con la sanción de la ley pasó a llamarse Departamento General de Inmigración, denominación con la que duraría muchas décadas.

${ }^{13}$ Editado como Wilcken (1873). 
tenida por útil para un inmigrante ${ }^{14}$. El tono es bastante uniforme y no se perciben mayores sesgos; apenas es de destacar el fuerte optimismo que trasuntan los informes de las colonias santafesinas, propio de otras fuentes de la época sobre esos emprendimientos, y lógico en vista de su acelerado progreso. Existen cuadros anexos donde se volcaba la información, pero es en el texto mismo donde se encuentran los datos más valiosos para nuestro estudio: jornales, salarios mensuales y precios por unidad (minorista) de los alimentos de consumo popular. Hemos confrontado los datos que ofrece el informe con los provistos por otras fuentes de la época, y se mostraron siempre coincidentes ${ }^{15}$. Dado que se ofrecen rangos (es decir, la fuente informa precios máximos y mínimos de cada bien y salarios también máximos y mínimos por cada categoría) se optó por tomar el promedio simple; lamentablemente, al no contar con las planillas originales, no sabemos la cantidad de observaciones ni su varianza, pero los rangos no muestran casi nunca en cada ítem una amplitud mayor al 30\%. En los pocos casos en que ello sí ocurrió, se chequearon los valores con otras fuentes o con los de localidades cercanas, optándose por el menos divergente, ya fuera el promedio, el máximo o el mínimo ${ }^{16}$.

Para este trabajo pudieron aprovecharse los datos de los informes remitidos desde diecisiete localidades, que cubrían razonablemente las catorce provincias que en ese entonces formaban el país ${ }^{17}$. Solo quedaron fuera de consideración, por falta de datos útiles, los correspondientes a las ciudades de Santa Fe, Rosario, Gualeguaychú, San Luis y Córdoba, todas ellas incluyendo su área rural inmediata. Pero pudieron aprovecharse los correspondientes a las colonias de Roldán, Carcarañá y Cañada de Gómez (situadas en el sur de la provincia de Santa Fe, sobre la línea férrea que partía de Rosario y se encontraban entre 30 y 80 kilómetros de esta última); Goya (en la provincia de Corrientes); Paraná (Entre Ríos); Tucumán; Mendoza; Río Cuarto (Córdoba); Villa Mercedes (San Luis); Salta; La Rioja; Santiago del Estero; San Juan; Catamarca; Jujuy y Buenos Aires (de la cual

\footnotetext{
${ }^{14}$ En particular, los precios de los bienes, del ganado, las condiciones de acceso a la tierra, existencia de industrias, y los que nos interesan aquí: «14. Precio de los artículos de consumo y alquiler de casa para la clase obrera; 15. Salario ó jornal que puede ganar un artesano en los diversos ramos, y un jornalero, agricultor ó peón para todo trabajo» (Argentina. Comisión Nacional de Inmigración, 1876, pp. xxiv-xxv). Cfr. Alsina (1900, p. 84). Los formularios por los que en cada localidad se recogió la información no se han conservado, pero sin duda los datos sobre salarios fueron provistos por los propios empleadores, en tanto el comisario local concentraba los pedidos de trabajadores que luego eran remitidos al comisario general para ser publicados entre los inmigrantes arribados. Los precios de artículos de consumo, en tanto, seguramente fueron obtenidos de los mercados locales, que eran fiscalizados por los gobiernos respectivos para cobro de patentes.

${ }^{15}$ Por ejemplo, los salarios informados para Paraná, en Entre Ríos (entre 6 y 9 reales bolivianos por jornal, o sea entre 15 y 22,5 pesos bolivianos por mes, asumiendo 20 días de trabajo) coinciden con los pagados en un gran establecimiento rural privado de la zona (en promedio, para el año 1875, 18,3 pesos mensuales para las categorías más bajas, puesteros y peones). Estos últimos datos tomados de APSJ, DC, Caja 130, legs. 71 y 56; Caja 134, leg. 619.

${ }^{16}$ Por ejemplo, para los peones en Cañada de Gómez se informaron salarios mensuales de 10 a 18 pesos bolivianos "con casa y mantenimiento". Al ser la cifra máxima demasiado extemporánea a la luz de los datos de otras localidades cercanas, se optó por la mínima. Es probable que haya existido un error de transcripción y los 18 pesos fueran en realidad 13.

17 Se aclara que los datos corresponden a cada localidad, no a las regiones
} o provincias, aun cuando seguramente no diferirían demasiado. existen dos, uno correspondiente al área rural del norte del río Salado, y otro para la localidad de Tandil $)^{18}$.

Todos los valores fueron registrados en la moneda más usual a nivel local (peso boliviano, peso fuerte, peso moneda corriente), de modo que para homogeneizarlos se les convirtió a gramos de oro a través de la equivalencia de 21,06 pesos bolivianos, 17 pesos fuertes y 425 pesos moneda corriente de Buenos Aires, por una onza (hispanoamericana) de oro de 27,064 gramos, 872 milésimos de fino y ley de 21 quilates ${ }^{19}$.

\section{Los salarios}

En los informes se incluyen datos de jornales y salarios mensuales pagados por diversos tipos de trabajo y profesiones. En algunos casos hay también información sobre remuneraciones a destajo. Se seleccionaron los datos correspondientes a las categorías más bajas de la escala laboral, que transcribimos tal como aparecen en la fuente: jornaleros, peones, peones para todo trabajo, peones generales, peones gañanes, peones de mano, peones para (trabajar cortando) quebracho colorado, peones accesorios, peones para trabajo de campo (en cosecha y en tiempo normal), peones para trabajo en la ciudad, peones de barraca, peones para agricultura, peones zanjeadores, obreros, albañiles, mucamos. Si bien no se trata de lo mismo, de todos modos las diferencias entre esas categorías no fueron significativas ${ }^{20}$. Dejamos de lado así una gran variedad de ocupaciones, la casi totalidad de ellas relacionada con el trabajo manual y en categorías bajas de la escala ocupacional, pero que implicaban algún tipo de diferencial salarial no relacionado con cuestiones estacionales (por ejemplo: mozos de tienda, almacén, confitería; cocineros; carpinteros; herreros; tipógrafos; mozos de billar; curtidores; peones de carnicería, panadería o molinería; artesanos; zapateros; etc.). Esa diversidad, y la falta de descripciones más detalladas de cada oficio, impidió, al menos aquí, utilizar la información correspondiente a diferenciales salariales por habilidad (skill premium), aun cuando la misma podría ser calculada para algunas localidades, involucrando, por ejemplo, tareas de oficiales herreros o carpinteros y maestros, las más abundantes.

\footnotetext{
${ }^{18}$ En los casos de las localidades cuyos datos pudimos aprovechar, cuando no se menciona entre paréntesis la provincia respectiva, debe entenderse que se trata de la que tiene el mismo nombre que la localidad analizada. Las subcomisiones de Baradero, San Pedro y San Nicolás enviaron un solo informe en conjunto; los precios y salarios allí incluidos no indican a qué localidad correspondían (las variaciones rondan el 25-30\%). Para aprovechar los datos se tomó el promedio, refiriéndolo a la región norte de la provincia de Buenos Aires, que es donde se encuentran esas localidades. ${ }^{19}$ La antigua onza (o doblón de ocho escudos) acuñada en la América colonial hispánica tuvo inicialmente una ley de $233 / 4$ quilates, rebajada sucesivamente en $1771 ; 1785 ; 1796$ y 1825, hasta llegar a 21 quilates (Burzio, 1958, t. I, pp. 150 y ss.; Vendrell, 1829, p. 192) La provincia de Buenos Aires abandonó el patrón plata en 1864 al adoptarse como unidad de cuenta (imaginaria) el peso fuerte oro, a 17 por onza. En septiembre de 1875 el Estado nacional estableció asimismo el peso fuerte oro como unidad de cuenta. Las cotizaciones provienen de: peso boliviano contra onza, datos amablemente cedidos por Juan Luis Martirén; peso fuerte contra onza, Agote (1881); peso moneda corriente de Buenos Aires contra onza, tablas de Alvarez (1929). Entre 1867 y 1876 existió convertibilidad fija de la moneda porteña.

${ }^{20}$ Por ejemplo, en Goya los peones de albañil ganaban lo mismo que los "peones en general», y un poco más que los "peones para trabajo de campo»; en Tandil, los albañiles y los mucamos ganaban lo mismo que los "peones de patio» y los "para todo trabajo».
} 
Tabla 1

Datos de los diversos distritos analizados

\begin{tabular}{|c|c|c|c|c|c|}
\hline $\begin{array}{l}\text { Ciudad o área (entre paréntesis los números } \\
\text { de las localidades del mapa) }\end{array}$ & $\begin{array}{l}\text { Población total } \\
\text { de la localidad }\end{array}$ & Familias & Peones & $\begin{array}{l}\text { Individuos } \\
\text { por familia }\end{array}$ & $\begin{array}{l}\text { Peones } \\
\text { por familia }\end{array}$ \\
\hline Rosario rural, Santa Fe $(1 ; 2 ; 3)$ & 26.323 & 4.093 & 3.815 & 6,43 & 0,93 \\
\hline Paraná, Entre Ríos (5) & 17.951 & 3.166 & 2.000 & 5,67 & 0,63 \\
\hline Tucumán, Tucumán (6) & 37.559 & 5.464 & 1.812 & 6,87 & 0,33 \\
\hline Rio Cuarto, Córdoba (8) & 10.995 & 1.812 & 753 & 6,07 & 0,42 \\
\hline Villa Mercedes, San Luis (9) & 2.033 & 463 & 382 & 4,39 & 0,83 \\
\hline Salta, Salta (10) & 16.877 & 2.683 & 868 & 6,29 & 0,32 \\
\hline La Rioja, La Rioja (11) & 5.632 & 863 & 226 & 6,53 & 0,26 \\
\hline Jujuy, Jujuy (15) & 7.629 & 1.308 & 345 & 5,83 & 0,26 \\
\hline Buenos Aires, norte del Salado (rural) (16) & 74.154 & 12.567 & 10.957 & 5,90 & 0,87 \\
\hline
\end{tabular}

Notas: «Población total» corresponde a todos los habitantes de la localidad. Es de destacar que, aun cuando la proporción de viudos o solteros es relevante, de todos modos estos muy pocas veces constituían familias unipersonales. «Peones» refiere, según la fuente, a «jornaleros, peones, etc.», es decir, se trata de todos aquellos trabajadores sin calificación que dependen de un jornal o salario mensual. Los datos se tomaron mayormente de la fuente impresa, pero en algunos pocos casos fue necesario desagregarlos a partir de las fichas censales. Los datos del censo no desagregan la localidad de Tandil, por lo que no fue incluida en el cuadro. Se tomó para la misma el promedio del área rural de la provincia de Buenos Aires.

Fuente: De la Fuente (1872) y fichas manuscritas del censo de 1869, en AGN.

Hemos aprovechado tanto los datos de jornales como de salarios mensuales, sin uniformarlos en una única categoría porque las diferencias entre ambos tipos de contrato eran significativas $^{21}$. Dado que los jornaleros no necesariamente trabajaban todos los días del mes, hemos supuesto que lo hacían durante veinte días para conformar su ingreso mensual, el cual será la base del cálculo de la cobertura alimentaria ${ }^{22}$. Es importante remarcar que la fuente especifica si, además del pago en dinero correspondiente a los salarios o jornales, se agregaba la alimentación y el alojamiento del trabajador, como era usual en buena parte de los casos. En los informes hay asimismo datos de alquiler de cuartos o casas, pero no todas las localidades cuentan con información homogénea al respecto ${ }^{23}$. Tampoco hay datos suficientes sobre vestimenta y otros bienes no imprescindibles, de modo que no construiremos canastas de consumo más allá de las correspondientes a la pura supervivencia alimentaria.

Antes de continuar, es preciso establecer la representatividad del salario como ingreso, y de la forma laboral del peón/

\footnotetext{
${ }^{21}$ Los problemas de utilizar salarios mensuales como insumo para cálculos de bienestar han sido destacados por Djenderedjian y Martirén (2016).

${ }^{22}$ Este supuesto no es arbitrario; los estudios disponibles han contabilizado un promedio de veinte días laborables por mes, que es asimismo el promedio de días trabajados por los jornaleros en obras públicas. Ver, por ejemplo, Moraes y Thul (2016, p. 10).

${ }^{23}$ De todos modos, hay información sobre alquiler de una habitación en un edificio céntrico para cinco localidades (Mendoza, La Rioja, Río Cuarto, Paraná, Tucumán). Tomando el valor menor informado (que va de 2 a 6,17 pesos bolivianos, o entre 0,03 y 0,09 gramos de oro) los resultados indican un costo que ronda entre el 2 al $4 \%$ del valor de la canasta alimentaria mensual, salvo el caso de La Rioja, donde ese monto llega al 17\%.
}

jornalero a salario como parte de los modos de ganarse la vida. La tabla anterior, elaborada a partir de los datos del censo nacional de 1869, muestra la proporción de individuos por familia y la de jornaleros por familia en cada una de las localidades analizadas. Como puede verse, la dispersión es muy grande: las familias van desde 4,39 miembros por unidad (Villa Mercedes, San Luis) hasta 7,4 (Goya, Corrientes). Por otro lado, la cantidad de jornaleros por familia, sin llegar nunca a la unidad, corre también entre un amplio espectro que va desde 0,16 (San Juan) hasta 0,83 (Villa Mercedes, San Luis), 0,87 (Buenos Aires) o 0,93 (área rural del departamento Rosario). No existe correlación (coeficiente -0,61) entre tamaño de la familia y cantidad de jornaleros; en todo caso, es evidente que a mayor cantidad de miembros estos no necesariamente buscaban su sustento como peones asalariados. Es decir, algo que muchos trabajos han puesto ya de relieve: la cantidad de cuentapropistas o "patrones» era proporcionalmente muy alta en el Río de la Plata; al menos en comparación con las áreas más dinámicas (Buenos Aires, Santa Fe, Mendoza, Villa Mercedes, Paraná) la proporción de asalariados es mayor; en otras lo es mucho menos, mostrando con claridad un marcado clivaje, también mencionado por la historiografía ${ }^{24}$. Retengamos esta imagen para lo sucesivo.

La siguiente tabla muestra los ingresos salariales de las categorías más bajas, que hemos seleccionado según los criterios ya especificados. Los montos respectivos han sido convertidos a gramos de oro y se detallan asimismo los casos en los cuales se proveía además la comida.

\footnotetext{
${ }^{24}$ Por ejemplo, Gelman (2010, pp. 71-104); Garavaglia (1999).
} 


\section{Tabla 2}

Ingresos (peón, albañil, mucamo) en gramos de oro

\begin{tabular}{|c|c|c|c|c|}
\hline & $\begin{array}{l}\text { Por } \\
\text { día }\end{array}$ & $\begin{array}{c}c / \\
\text { comida }\end{array}$ & $\begin{array}{l}\text { Por } \\
\text { mes }\end{array}$ & $\begin{array}{c}c / \\
\text { comida }\end{array}$ \\
\hline 1. Roldán & & & 19,94 & \\
\hline 2. Carcarañá & & & 19,94 & \\
\hline 3. Cañada de Gómez & & & 20,68 & $\mathrm{Si}$ \\
\hline 4. Goya & 1,94 & & 12,81 & $\mathrm{Si}$ \\
\hline 5. Paraná & 1,37 & & & \\
\hline 6. Tucumán & & & 19,94 & $\mathrm{Si}$ \\
\hline 7. Mendoza & 2,22 & & 14,77 & $\mathrm{Si}$ \\
\hline 8. Río Cuarto & 1,11 & & 14,77 & $\mathrm{Si}$ \\
\hline 9. Villa Mercedes & 1,48 & & 25,85 & $\mathrm{Si}$ \\
\hline 10. Salta & 1,29 & & 22,15 & \\
\hline 11. La Rioja & 0,74 & $\mathrm{Si}$ & & \\
\hline 12. Santiago del Estero & 0,74 & $\mathrm{Si}$ & 21,96 & \\
\hline 13. San Juan & & & 11,08 & $\mathrm{Si}$ \\
\hline 14. Catamarca & & & 25,85 & \\
\hline 15. Jujuy & 1,48 & & & \\
\hline $\begin{array}{l}\text { 16. Buenos Aires rural, } \\
\text { norte del Salado }\end{array}$ & 2,29 & & 25,61 & \\
\hline 17. Tandil & 2,20 & & 29,27 & \\
\hline
\end{tabular}

Fuente: Argentina. Comisaría General de Inmigración. (1876, passim).

\section{Los alimentos}

La fuente nos provee abundantes datos en torno a tipo, calidad y precio de los principales alimentos que, según los distintos informantes, eran consumidos por los trabajadores. Hemos completado los pocos datos que allí no aparecían con los de otras fuentes de la época ${ }^{25}$. Los precios informados son en general en medida minorista (libra, almud, botella), pero en algunos casos están en medida mayorista (arroba, fanega, cuarta). De todos modos, cuando esto último ocurre los propios informantes no establecen demasiadas diferencias entre unos y otros a la hora de calcular el gasto del trabajador, por lo que suponemos que aun cuando la medida sea mayorista, los precios corresponden a los de venta al público. Se informan asimismo para ciertos puntos las diferencias entre precios de verano y de invierno, que en algún caso llegan al doble (Mendoza). En esos casos se optó por el promedio. La carne, en general, es de vacuno, pero en ciertos casos (las colonias agrícolas de Santa Fe, con buena parte de su población inmigrada de Europa del Norte) se informan además los valores de carne de cerdo u ovino, optándose por incluir la primera si esa información estaba disponible. En función de una canasta básica, se seleccionaron distintos alimentos cuyos precios se encontraban en la fuente y figuran en la siguiente tabla.

${ }^{25}$ En concreto, los precios de la carne en Tandil se calcularon a partir de la proporción existente en Buenos Aires entre los de la carne y los del ganado vacuno (novillos y vacas) destinado a mataderos, que aparecía regularmente en los Anales de la Sociedad Rural Argentina.

Tabla 3

Precios de alimentos (en gramos de oro por kilo)

\begin{tabular}{|c|c|c|c|c|c|c|c|c|c|c|c|}
\hline & Carne & Cerdo & Pan & Harina & Trigo & Maíz & Arroz & Cebada & Grasa & Papas & Mandioca \\
\hline 1. Roldán & 0,12 & 0,45 & & & 0,10 & & & & & & \\
\hline 2. Carcarañá & 0,12 & & & & 0,09 & & & 0,03 & & & \\
\hline 3. Cañada de Gómez & 0,16 & & & & & 0,11 & & 0,05 & & & \\
\hline 4. Goya & 0,11 & & & 0,40 & & & 0,30 & & & & \\
\hline 5. Paraná & 0,14 & & 0,32 & & & & 0,26 & & 0,51 & & \\
\hline 6. Tucumán & 0,32 & & 0,60 & & & & 0,39 & & & & \\
\hline 7. Mendoza & 0,26 & & & 0,16 & & & & & & 0,06 & \\
\hline 8. Río Cuarto & 0,18 & & & & & 0,10 & & & & & \\
\hline 9. Villa Mercedes & 0,10 & & & & & 0,10 & & & & & \\
\hline 10. Salta & 0,21 & & & 0,45 & & 0,08 & & 0,07 & & & \\
\hline 11. La Rioja & 0,48 & & 0,50 & & & & 0,80 & & 0,80 & & \\
\hline 12. Santiago del Estero & 0,40 & & 0,64 & & & & 0,60 & & & & \\
\hline 13. San Juan & 0,32 & & & & 0,13 & & & & & & \\
\hline 14. Catamarca & 0,23 & & & & 0,10 & 0,08 & & 0,06 & & & \\
\hline 15. Jujuy & 0,19 & & 0,20 & & & & & & & & 0,12 \\
\hline 16. BA rural N. Salado & 0,21 & & & 0,16 & 0,07 & 0,02 & & & & & \\
\hline 17. Tandil & 0,13 & & & & 0,11 & 0,07 & & & & & \\
\hline
\end{tabular}

Fuente: Argentina. Comisaría General de Inmigración (1876). 
Tabla 4

Calorías (por 100 gramos)

\begin{tabular}{cccccccccccc}
\hline Carne & Cerdo & Pan & Harina & Trigo & Maíz & Arroz & Cebada & Grasa & Papas & Mandioca \\
\hline 155 & 143 & 272 & 361 & 339 & 365 & 101 & 123 & 902 & 265 & 330 & \\
\hline
\end{tabular}

Fuente: referencias estándar en la página web del USDA (United States Department of Agriculture), en https://ndb.nal.usda.gov/ndb/foods/, consultado en: diciembre 2017. En el caso de la carne vacuna se optó por la categoría 23381, «Beef, round, eye of round steak, boneless, separable lean only, trimmed to 0 fat, all grades, cooked, grilled».

El componente calórico de cada uno de ellos, que se muestra en la tabla 4, se tomó de las referencias estándar publicadas en la página web del USDA.

\section{Las canastas}

Con todos esos datos se construyeron canastas de consumo mínimo familiar para cada una de las localidades analizadas. La fuente informa el costo global de una canasta típica en Buenos Aires, pero no conocemos su composición en cada localidad ${ }^{26}$. Se optó así por una distribución razonable bajo las siguientes pautas: a) estructura basada en dos bienes alimenticios principales (carne vacuna y un farináceo), según han reportado estudios disponibles para la región y graduando las cantidades en función de estos (por ejemplo, Moraes y Thul 2017; Cortés Conde 1979; Santilli y Gelman 2016; Bragoni y Olguín 2016); b) dar prioridad en cada localidad al bien que ofrezca mejor relación aporte calórico/precio, y c) reflejar en lo posible los condicionantes culturales locales. De allí el destacado papel de la carne vacuna, bien de equilibrio por su muy bajo precio relativo, salvo en Salta, Catamarca y Jujuy, donde este era más alto, y en la zona de colonias de Santa Fe, donde por pautas culturales era más frecuente consumir cerdo y cereales diversos. Es de destacar que la misma selección de alimentos que ofrece la fuente, con sus respectivos precios, sigue las pautas que los comisarios que recogieron los datos consideraban más comunes entre la población trabajadora, y ello más allá de si los lectores finales de la publicación fueran nacionales o extranjeros, ya que muy a menudo los bienes informados son los típicos preferidos de la población criolla ${ }^{27}$. Las canastas así podrían sin duda ser diferentes, pero consideramos que presentan razonablemente una selección básica para cubrir el umbral de 1941 calorías que conforman la canasta de subsistencia o bare bones basket (BBB $)^{28}$.

Tabla 5

Composición de las canastas (en gramos)

\begin{tabular}{|c|c|c|c|c|c|c|c|c|c|c|c|}
\hline & Carne & Cerdo & Pan & Harina & Trigo & Maíz & Arroz & Cebada & Grasa & Papas & Mandioca \\
\hline 1. Roldán & 400 & 47 & & & 370 & & & & & & \\
\hline 2. Carcarañá & 400 & & & & 320,6 & & & 190 & & & \\
\hline 3. Cañada de Gómez & 400 & & & & & 260,9 & & 300 & & & \\
\hline 4. Goya & 600 & & & 112,2 & & & 600 & & & & \\
\hline 5. Paraná & 600 & & 190 & & & & 70 & & 47 & & \\
\hline 6. Tucumán & 450 & & & 180 & 46,5 & 100 & 70 & & & & \\
\hline 7. Mendoza & 500 & & & 180 & & & & & & 195 & \\
\hline 8. Río Cuarto & 500 & & & & & 319,5 & & & & & \\
\hline 9. Villa Mercedes & 550 & & & & & 298,3 & & & & & \\
\hline 10. Salta & 400 & & & 100 & & 200 & & 187 & & & \\
\hline 11. La Rioja & 500 & & 124,5 & & & & 400 & & 47 & & \\
\hline 12. Santiago del Estero & 600 & & 170 & & & & 543 & & & & \\
\hline 13. San Juan & 500 & & & & 344 & & & & & & \\
\hline 14. Catamarca & 350 & & & & 100 & 273,5 & & 50 & & & \\
\hline 15. Jujuy & 350 & & 100 & & & & & & & & 341,5 \\
\hline 16. BA rural n. Salado & 500 & & & 150 & 50 & 124,7 & & & & & \\
\hline 17. Tandil & 500 & & & & 200 & 133,7 & & & & & \\
\hline
\end{tabular}

Nota: se trata de las cantidades mínimas diarias en gramos de cada alimento a consumir por un adulto varón equivalente a fin de alcanzar 1941 calorías. Fuente: Argentina. Comisaría General de Inmigración (1876).

\footnotetext{
${ }^{26}$ Argentina. Comisaría General de Inmigración. (1876, pp. XIII-XIV). La canasta era la ofrecida a los inmigrantes a su arribo a Buenos Aires, y se componía de carne, verduras, arroz, café, azúcar, pan, carbón y sal. Suponía 2600 calorías aproximadamente y su costo era de 33,75 reales moneda corriente, o sea 0,31 gramos de oro.
}

${ }^{27}$ Así, se ofrecen datos de yerba mate, maíz, pan con grasa, mandioca, etc. Algunos de ellos no fueron incluidos en aras de simplificar las distintas canastas locales. La carne barata es una característica de casi toda el área estudiada, y la diferencia netamente de Europa, donde era un bien de alto precio.

${ }^{28}$ Como se ha dicho, ese umbral fue definido por Allen (2001), quien a su vez se basó en cálculos previos de Fogel (1991). 
Tabla 6

Aporte calórico de las canastas

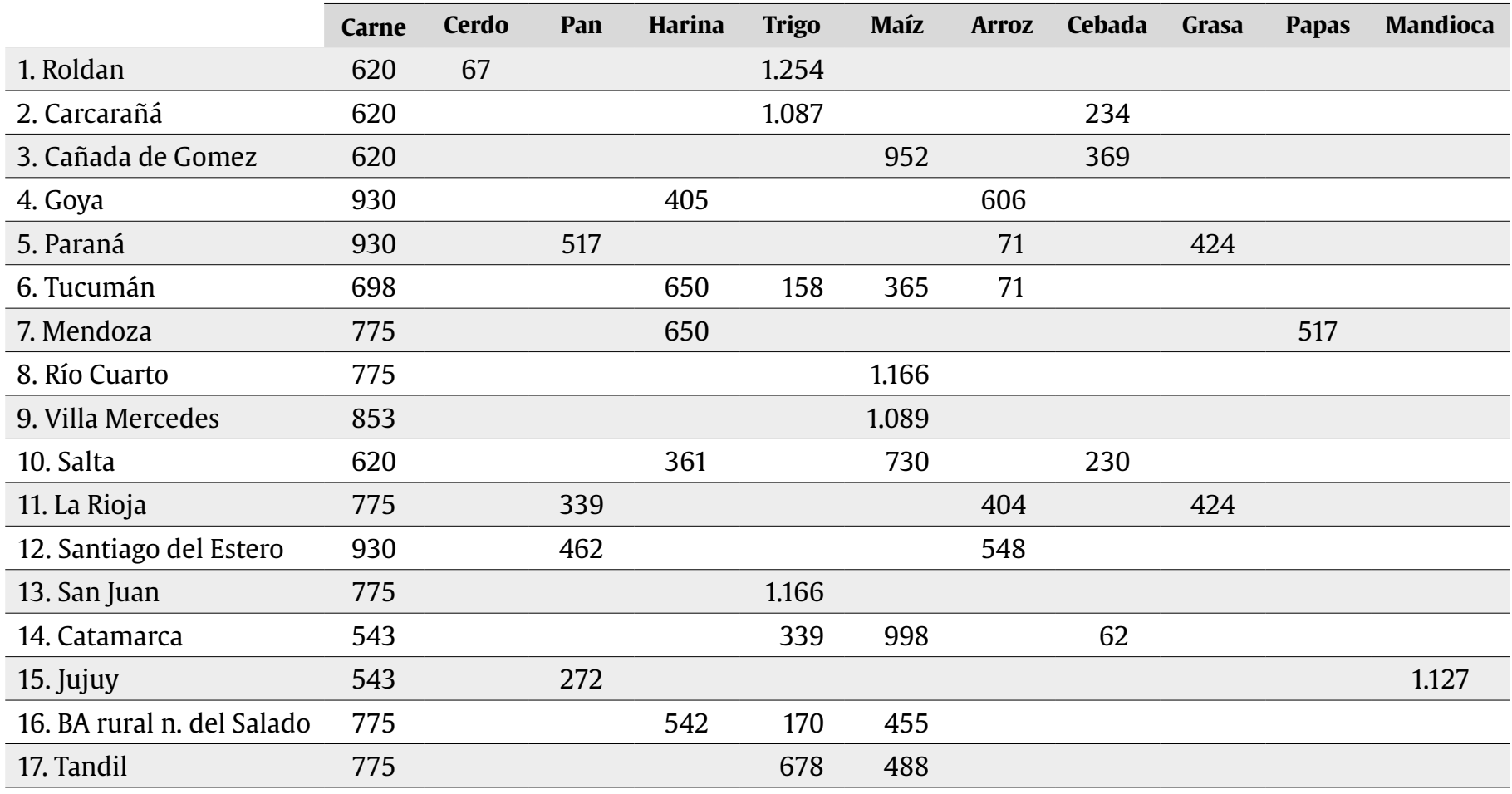

Fuente: Argentina. Comisaría General de Inmigración. (1876).

Como estamos relacionando canastas de consumo de alimentos con jornales y salarios mensuales, es menester tener en cuenta si la alimentación del trabajador era o no provista por su empleador. De ese modo, según los casos en que sí lo fuera y que detallamos en la tabla 2 , hemos agregado una canasta más como ingreso familiar neto a su valor monetario, aun cuando sabemos por diversos testimonios que los alimentos recibidos en el lugar de trabajo superaban con mucho las calorías de una canasta de subsistencia ${ }^{29}$. Por otro lado, no todos los miembros de la familia tienen la misma edad ni las mismas necesidades calóricas. Para solucionar ese problema, adoptamos la distribución de las mismas que figura en la tabla 7, en función de una familia promedio de seis miembros.

Pero además de la composición familiar, es menester tener en cuenta el hecho de que un solo salario no era usualmente el único ingreso de la misma. De ese modo, si consideramos un grupo familiar compuesto, en promedio, por entre cinco y seis personas, es muy probable que incluyera algún adulto o adolescente en condiciones de trabajar, ya fuera porque aún hubiera ascendientes directos formando parte del grupo nuclear o porque alguno de los hijos hubiera ya alcanzado edad

\footnotetext{
${ }^{29}$ Moraes y Thul (2017) para Montevideo, 1770-1810 y Bialet Massé (1904, II, pp. 216-218) para diversos puntos del interior argentino en 1887-1903 coinciden en reportar canastas de 3000 calorías o más provistas por patrones rioplatenses a sus trabajadores. Hemos visto en la nota 26 que la ración dada en 1875 por la Comisión a los inmigrantes al llegar a Buenos Aires sumaba alrededor de 2600 calorías. No hay razones para pensar que las usuales otorgadas por empleadores a sus peones a lo largo del resto del siglo xIX variaran demasiado de esos rangos.
}

suficiente para ello. Lo cual se refleja en la tabla 7 con la presencia de un adulto que suponemos mayor de 40 años, pero cuyo consumo calórico también podría ser el de un joven menor de 20. Y si consideramos su consumo, deberíamos asimismo considerar su ingreso.

Por tanto, el ingreso familiar se compondrá, para nosotros, de: a) el salario de uno de sus miembros adultos; b) los alimentos que se le proveen a este en forma de ración, si están incluidos en el contrato, y c) los ingresos de otro u otros miembros del grupo familiar, que por razones prácticas resumiremos en un salario más, aun cuando, como es lógico, puedan incluirse allí expedientes de muy diversa índole: empleo circunstancial de los muchachos jóvenes en tareas de baja calificación, venta de artesanías, producción de hortalizas, comercio a pequeña escala, empleo formal de un miembro adulto, etc. Pero dado que ello debe estar en relación con el tamaño de la familia, se agregará el ítem c) únicamente en los casos en que la misma cuente con cinco o más miembros ${ }^{30}$.

Hemos volcado a la tabla 8 la información correspondiente, y calculado la cantidad de canastas de subsistencia cubiertas por el ingreso familiar, fuera este jornal o salario mensual. Agrega-

\footnotetext{
${ }^{30}$ Solo Villa Mercedes (San Luis) tiene un promedio de miembros por familia menor de 5 (en rigor, 4.39), por lo que allí no se contabilizará el sueldo extra c). El hecho de considerar un salario completo más como ingreso puede ser discutible, ya que no es probable que ambos miembros de la familia ganen lo mismo a causa de diferencias de edad o de calificación o que lo hagan durante todo el año. Pero de todos modos creemos que es un supuesto conservador porque más de dos miembros de la familia podrían tener ingresos eventuales o regulares o uno de ellos ganar más que el salario/jornal mínimo en determinados momentos del año (por ejemplo, la época de cosecha o zafra lanera).
} 
Tabla 7

Composición calórica de una canasta de subsistencia para una familia de seis miembros. Argentina, 1875

\begin{tabular}{lcr}
\hline $\begin{array}{l}\text { Miembros de } \\
\text { la familia }\end{array}$ & $\begin{array}{c}\text { Proporción del gasto calórico per cápita en porcentaje del equivalente } \\
\text { al de un adulto masculino }\end{array}$ & $\begin{array}{c}\text { Calorías } \\
\text { por persona }\end{array}$ \\
\hline Padre (20-39) & 1,000 & $1.941,00$ \\
\hline Madre (20-39) & 0,733 & $1.422,75$ \\
\hline 1 adulto (40-49) & 0,823 & $1.598,12$ \\
\hline 1 niño (0-4) & 0,439 & 852,10 \\
\hline 1 niño $(0-4)$ & 0,439 & 852,10 \\
\hline 1 niño $(0-4)$ & 0,439 & 852,10 \\
\hline Total & $\mathbf{3 , 8 7 3}$ & $\mathbf{7 . 5 1 8 , 1 7}$ \\
\hline
\end{tabular}

Fuente: proporción del gasto calórico según Floud et al. (2012, p. 46). Se tomó el promedio de masculino y femenino en los miembros 3 a 6 . Se prefirió asignar edad 0-4 a los niños para reflejar no solo la tasa de dependencia, sino, sobre todo, porque se supone que un asalariado es en promedio una persona joven en los estadios iniciales de su vida laboral y familiar, y por tanto con hijos pequeños.

Tabla 8

Cobertura de canastas de subsistencia por parte de ingresos familiares. Argentina, 1875

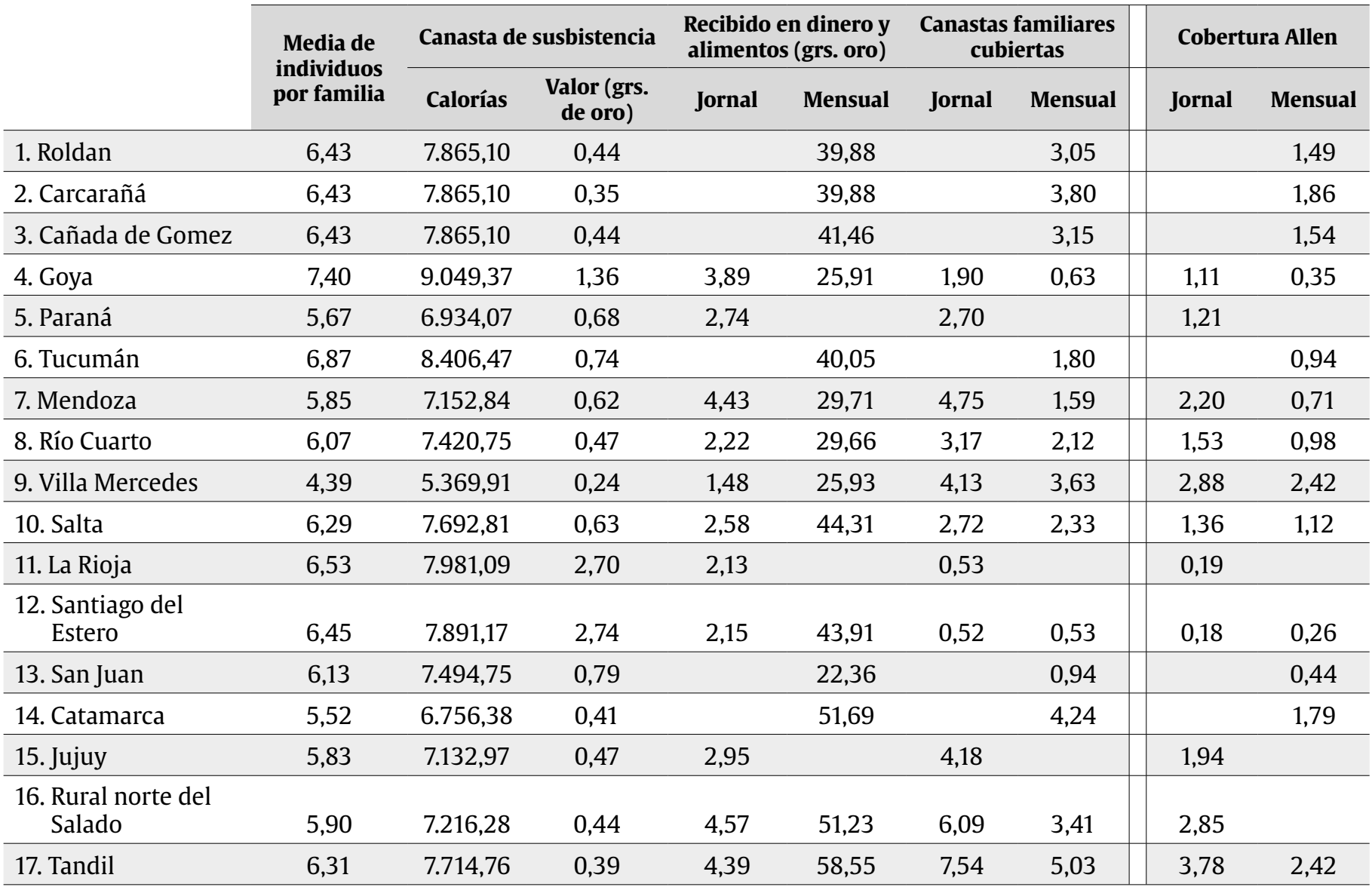

Nota: las canastas de subsistencia familiares cubiertas se calcularon dividiendo el ingreso mensual (los jornales multiplicados por 20) por el importe de la canasta familiar mensual, obtenida multiplicando por 30 el valor diario en gramos de oro. «Cobertura Allen» corresponde a los índices de bienestar elaborados bajo las pautas de Allen (2001), es decir: a) considerando familias de 4 miembros (3,15 adultos equivalentes), o necesidades calóricas uniformes para todas las localidades de 6114 calorías por familia; b) agregándole al costo en dinero de esa ingesta calórica un $25 \%$ más a fin de cubrir los gastos de jabón, lienzo, velas, aceite de lámpara y combustibles, y c) agregándole a esa suma un $5 \%$ más, a fin de reflejar el costo de alquiler de habitación. A su vez, d) compara el ingreso de un solo miembro varón, ya fuera jornal o salario mensual (el primero, a 250 días por año), y sin tener en cuenta la provisión de alimentos por parte del empleador. Ese $25 \%$ que hemos adicionado para cubrir los gastos de vestimenta, lumbre y demás equivale a la proporción de esos rubros en la canasta de Allen (2001), pero el costo del combustible era en Argentina mucho menor que en Europa porque existían aún inmensos bosques mostrencos, y gozaban de temperaturas promedio más cálidas; el jabón y el aceite de alumbrado se obtenían de los abundantes ganados; las necesidades de prendas de vestir eran asimismo menores, aun cuando sus precios pudieran haber sido más caros que en Europa, de donde provenía buena parte de las mismas. De ese modo, el $25 \%$ aludido es seguramente un valor máximo. En tanto, el $5 \%$ para costo de vivienda es también un valor máximo, ya que, por los indicios que poseemos, el alquiler de un cuarto en varias de las localidades que estudiamos aquí no llegaba al 3\% o 4\% del valor de la canasta. 
mos, asimismo, en las dos últimas columnas la cobertura según la propuesta de Allen (2001), supliendo la falta de datos de combustible, alumbrado y ropa con la proporción de gasto en los mismos utilizada por ese autor, aun cuando aquí el costo pueda haber sido menor. Y, si bien no en todos los casos los jornales y salarios corresponden a trabajadores de la construcción, de todos modos los utilizados no difieren demasiado de estos (véase la nota 20). El resultado es bastante heterogéneo.

Así, desde un mínimo de media canasta a máximos de más de siete, la dispersión es muy llamativa. Empleando la metodología de Allen (2001), las diferencias con nuestro cálculo (que consideramos más realista) son bastante significativas, pero de todos modos siguen mostrando que los niveles de vida en Argentina eran muy diferentes según la localidad. Eso sí, tomando siempre el máximo de canastas cubiertas, la cantidad de ciudades mejor posicionadas que sus similares europeas en el período 1850-1899 se reduce a solo cuatro (Buenos Aires rural al norte del Salado, Tandil, Villa Mercedes, Mendoza), mientras que aumenta a diez según nuestro método (agregándose las tres colonias de Santa Fe, Catamarca, Jujuy y Córdoba ${ }^{31}$. Ello no está reñido con la realidad (en esos años las corrientes migratorias hacia Argentina coincidían bastante bien, en cuanto a su lugar de origen, con las ciudades cuyo nivel de vida igualaban o superaban las localidades que hemos estudiado aquí). Pero no significa que los números de una gran capital puedan dar cuenta aproximada de los de todo un país. Las grandes urbes, con economías de aglomeración y sofisticados desarrollos industriales y de servicios, son solo una parte del panorama, $\mathrm{y}$, para tiempos anteriores al siglo $\mathrm{xx}$, apenas vivía en ellas una porción menor de la población. Si además se trata de ciudades con puertos de ultramar o importantes nudos de comunicación, es probable que solo sean representativas de sí mismas. Como puede verse, las variadas localidades de un extenso país en formación -algunas de ellas recientes, otras antiguas, unas con alta proporción de extranjeros, otras pobladas por criollos- podían mostrar niveles de vida muy distintos. A lo largo de las décadas que restarán hasta el final del siglo XIX, esas diferencias se irían atenuando por la modernización de las comunicaciones y la conformación de mercados nacionales de factores, pero deberíamos tener en cuenta esa diversidad a la hora de analizar períodos previos ${ }^{32}$.

\section{Conclusiones}

Aun cuando casi siempre el ingreso salarial logra cubrir las necesidades básicas de todo el grupo familiar (y muy a menudo de varias familias), es de destacar la enorme heterogeneidad de este espacio: nada sorprendente para un historiador, dado que tratamos con economías orgánicas y mercados de bienes y factores aún poco integrados. La disparidad de ingresos según se trate de contratos a jornal o a salario mensual es asimismo muy fuerte, siendo los primeros más altos a proporción que los últimos. Ello es un derivado, en primer lugar, del peso de las tareas estacionales, pero también de la misma hetero-

\footnotetext{
31 Los datos de las ciudades europeas en Allen (2001, p. 426).

32 Por ejemplo, los índices de precios tenderán a converger; los datos de 1875 para las localidades que hemos analizado aquí arrojan un coeficiente de variación de 0,49, mientras que el promedio de 1903-1912 es de 0,11 (Correa Deza y Nicolini, 2014).
}

geneidad estructural ya mencionada ${ }^{33}$. En las áreas más dinámicas, la proporción de jornaleros era también más alta: en Buenos Aires rural, Villa Mercedes, Mendoza, Paraná y las colonias santafesinas esa proporción no bajaba nunca del $11 \%$, llegando incluso al $18 \%$. En cambio, en las menos dinámicas (y de menores índices de bienestar) era solo del $2 \%$ o el $4 \%{ }^{34}$. Ese clivaje tan estructural indica claramente que el jornal era más representativo del valor del trabajo sobre todo en las primeras, y que el salario mensual, en realidad, estaba en parte ligado a otro tipo de recompensas, como la fidelidad o la estabilidad. En un país aún muy diverso como era la Argentina de 1875, esas diferencias podían ser muy fuertes; se advierte así la necesidad de conocer con claridad los términos de las comparaciones y los detalles de los casos.

Hay que considerar, asimismo, otras dimensiones: las zonas más o menos urbanizadas, la mayor o menor inversión de capital, el tipo de actividad dominante, solo por mencionar algunas. En todo caso, parece también claro que existían fuertes diferencias económicas y culturales entre las áreas con mayor proporción de asalariados y las restantes: el coeficiente de correlación entre porcentaje de asalariados y poder adquisitivo del salario es fuertemente positivo para los jornales $(0,76)$ y algo menos, pero igualmente positivo, para los salarios mensuales $(0,63)$. Es decir, en donde el salario está más difundido como fuente de ingreso, cubre también mayor cantidad de canastas; es por tanto más representativo del ingreso familiar. Lo cual nos alerta nuevamente en torno a las porciones de territorio donde ello no ocurría: las gentes vivían sin duda de otras cosas, y ello no significaba necesariamente que no alcanzaran a cubrir sus necesidades básicas. Por el contrario, si bien hay homogeneidad entre las áreas de emigración y aquellas donde el poder adquisitivo del salario es menor, incluso en las localidades peor situadas en la tabla (Corrientes, Santiago del Estero o La Rioja) hay crecimiento poblacional consistente en el período intercensal 1869-1895; gozaban, por tanto, de niveles de bienestar superiores a la subsistencia ${ }^{35}$.

En segundo lugar, esa gran diferencia ya no es simplemente entre el litoral y el interior, como tradicionalmente se planteó en la historiografía argentina; la diversidad está marcada por el dinamismo de las economías regionales: el área pampeana, por ejemplo, de la cual comparten rasgos las localidades de Buenos Aires, Santa Fe, Río Cuarto, Paraná, en parte Villa Mercedes; además, el oasis de Mendoza y, a un nivel menos brillante pero no desdeñable, algunas áreas con recursos mineros y mercantiles, como Catamarca, Salta, Jujuy y hasta cierto punto Tucumán. Por otro lado, en las áreas menos dinámicas la

\footnotetext{
${ }^{33}$ En Mendoza, los altos precios de los productos en invierno explican parte de la diferencia entre jornales y salarios mensuales. Es probable que en Buenos Aires también pesaran mucho los jornales de época de zafra lanera o cosecha de trigo, históricamente muy altos con respecto a los del resto del año.

${ }^{34}$ Según el censo de 1869, en De la Fuente (1872).

${ }^{35}$ La población de La Rioja pasó de 48746 a 69502; la de Santiago del Estero de 132898 a 161502 , y la de Corrientes de 129023 a 239618, esta última con un crecimiento bastante llamativo del 2,3\% anual (De la Fuente, 1872; De la Fuente et al., 1898). Sobre el antiguo carácter de tierra de emigración en el caso de Santiago del Estero puede verse Farberman (1996). Migrantes de Corrientes eran comunes en la vecina Entre Ríos (Schmit, 2008). Asimismo, existía migración estacional hacia las áreas más dinámicas; por ejemplo, en la época de cosechas en la zona pampeana, o para la zafra azucarera en Jujuy (Adelman, 1992; Campi y Richard-Jorba, 2004).
} 
pobreza es estructural al explicarse no solo por salarios nominales más bajos, sino por precios relativos más altos de los alimentos. Por ello es que no ha sido posible encontrar, al menos en el abanico de bienes básicos ofrecido por la fuente, alternativas para conformar canastas más asequibles. Todo eso está además confirmado por los mismos informes de los comisarios regionales: se explica así el entusiasmo de quien escribe sobre Salta, de la cual indica que: «Un individuo puede mantenerse perfectamente con 4 reales diarios, y si es en familia con mayor razón [...] la casa habitación, según las condiciones y recursos del individuo, puede conseguirla hasta por un real diario [...]» En cambio, para La Rioja el informante reconocía honestamente que "la provincia [...] es de las más caras para vivir, puesto que el precio de los artículos no está en proporción con los gastos diarios del obrero [...]»36.

En tercer lugar, se comprueba que es muy imprudente asumir que la situación en la ciudad principal o capital de un vasto territorio pueda ser asimilada la totalidad de este. Basta comparar la diferencia entre los números de las localidades de Buenos Aires que analizamos aquí con los que resultarían si calculáramos la cobertura de las canastas de subsistencia para todo el país, ponderando el peso de cada región en base a la cantidad relativa de peones existente en ella: a jornal, la cobertura alcanzaría a 3,14; a salario mensual, a 2,04. En todo caso, ambas cifras muy distantes de las de 6,05 y 3,41 que corresponden a Buenos Aires en el área norte del Salado, la más cercana a la capital.

Para la comparación internacional, hemos propuesto aquí algunos ajustes a las estrategias más comúnmente empleadas. Ello deriva de la necesidad de repensar las categorías y los métodos que empleamos, máxime cuando las comparaciones se intentan entre realidades muy separadas en el espacio y en sus características económicas, sociales y culturales. Sobre todo, es preciso conocer en profundidad los casos que se analizan, no solo a través de bibliografía ad hoc, sino en su íntima capilaridad. De lo contrario, probablemente nuestros escarceos se debatirán en el vacío.

\section{Agradecimientos}

Deseo agradecer muy especialmente las críticas a versiones previas de este artículo hechas por Amílcar Challú, Juan Luis Martirén y los árbitros anónimos de la revista.

\section{Fuentes}

\section{Repositorios de fuentes manuscritas}

APSJ-DC: Archivo del Palacio San José, Entre Ríos, Argentina. Sección Dolores Costa.

\section{Fuentes publicadas}

Agote, P., 1881, 1882, 1885, 1887. Informe del presidente del Crédito Público [Nacional] D. Pedro Agote sobre la deuda pública, bancos y emisiones de papel moneda y acuñación de monedas de la República Argentina. La Tribuna Nacional; J. N. Klingelfuss; Guillermo Kraft, Buenos Aires.

\footnotetext{
${ }^{36}$ Argentina. Comisaría General de Inmigración (1876), vs. locs. Como hemos visto, incluso el alquiler de un cuarto era relativamente muy caro allí.
}

Alsina, J. A., 1900. La inmigración europea en la República Argentina. Imprenta México, Buenos Aires.

Argentina. Comisaría General de Inmigración, 1876. Informe anual del Comisario General de Inmigración de la República Argentina. Año 1875. Publicacion oficial. Imprenta Italiana, Buenos Aires.

Bialet Massé, J., 1904. Informe sobre el estado de las clases obreras en el interior de la República. Adolfo Grau, Buenos Aires.

De la Fuente, D. (dir.), 1872. Primer censo de la República Argentina verificado en los días 15, 16 y 17 de septiembre de 1869. Imprenta del Porvenir, Buenos Aires.

De la Fuente, D., Carrasco, G. y Martinez, A. (dirs.), 1898. Segundo censo de la República Argentina. Mayo 10 de 1895. Taller Tipográfico de la Penitenciaría Nacional, Buenos Aires.

Macdonell, H. G., 1872. Remarks on the River Plate Republics as a Field for British Emigration. Harrison and Sons, London.

Napp, R., 1876. La República Argentina. Sociedad Anónima, Buenos Aires.

Vendrell, J., [1829]. Curso teórico de aritmética mercantil. Imprenta Argentina, Buenos Aires.

Wilcken, G., 1873. Las colonias. Sociedad Anónima, Buenos Aires.

\section{Bibliografía}

Adelman, J., 1992. The Harvest Hand: Wage-Labouring on the Pampas, 1880 1914. En: Adelman, J. (ed). Essays in Argentine Labour History 1870-1930. McMillan, London.

Allen, R., 2001. The Great Divergence in European Wages and Prices from the Middle Ages to the First World War. Explorations in Economic History. 38, 411-447.

Álvarez, J., 1929. Temas de Historia Económica Argentina. El Ateneo, Buenos Aires.

Bragoni, B. y Olguín, P., 2016. Salarios, precios y nivel de vida en Mendoza durante la transformación vitivinícola (1890-1914). Folia Histórica del Nordeste. $26,156-177$.

Burzio, H. F., 1958. Diccionario de la moneda hispanoamericana. Fondo Histórico y Bibliográfico José Toribio Medina, Santiago de Chile.

Campi, D., 2004. La evolución del salario real del peón azucarero en Tucumán (Argentina) en un contexto de coacción y salario arcaico (1881-1893). América Latina en la Historia Económica. 11, 105-128.

Campi, D. y Richard-Jorba, R., 2004. Transformaciones productivas, espaciales y sociales en la Argentina extrapampeana: Tucumán y Mendoza entre 1850 y 1890. Boletín americanista. 54, 35-62.

Correa Deza, M. F. y Nicolini, E. A., 2014. Diferencias regionales en el costo de vida en Argentina a comienzos del siglo xx. Investigaciones de Historia Económica. 10 (3), 202-212.

Cortés Conde, R., 1979. El progreso argentino 1880-1914. Sudamericana, Buenos Aires.

Djenderedjian, J., Bearzotti, S. y Martirén, J. L., 2010. Expansión agrícola y colonización en la segunda mitad del siglo xIX. Historia del capitalismo agrario pampeano, t. VI. Teseo; Universidad de Belgrano, Buenos Aires.

Djenderedjian, J. y Martiren, J. L., 2016. Measuring living standards. Some caveats concerning salary elements in pre-modern Rio de la Plata region, 1770-1830. En: International Conference Old and New Worlds: the Global Challenges of Rural History, Lisbon, 27-30 January.

Dobado-González, R. y García-Montero, H., 2014. Neither So Low Nor So Short: Wages and Heights in Bourbon Spanish America from an International Comparative Perspective. Journal of Latin American Studies. 46, 1-31

Fogel, R. W., 1991. The Conquest of High Mortality and Hunger in Europe and America: Timing and Mechanisms. En: Higonnet, P., Landes, D. S. y Rosovsky, H. (eds.). Favorites of Fortune: Technology, Growth, and Economic Development since the Industrial Revolution. Harvard University Press, Cambridge, pp. 33-71.

Gelman, J., 2010. La gran divergencia. Las economías regionales en Argentina después de la Independencia. En: Bandieri, S. (comp.). La historia económica y los procesos de independencia en la América hispana. Prometeo, Buenos Aires.

Gelman, J. (dir.), 2011. Historia Contemporánea de Argentina. Tomo II, La Construcción Nacional, 1830-1880. MAPFRE, Madrid. 
Gelman, J. y Santilli, D., 2015. Salarios y precios de los factores en Buenos Aires, 1770-1880. Una aproximación a la distribución funcional del ingreso. Revista de Historia Económica. Journal of Iberian and Latin American Economic History. 33, 153-186.

Haber, S., 1997. How Latin America Fell Behind. Essays on the Economic Histories of Brazil and Mexico. Stanford University Press, Stanford.

Martirén, J. L., 2016. La transformación farmer. Colonización agrícola y crecimiento económico en la provincia de Santa Fe durante la segunda mitad del siglo XIX. Prometeo, Buenos Aires.

Farberman, J., 1995. Familia, ciclo de vida y economía doméstica. El caso de Salavina, Santiago del Estero, en 1819. Boletín del Instituto de Historia Argentina y Americana Dr. Emilio Ravignani. 12, 33-59.

Moraes, M. I. y Thul, F., 2017. Los salarios reales y el nivel de vida en una economía latinoamericana colonial: Montevideo entre 1760-1810. Revista de Historia Económica. Journal of Iberian and Latin American Economic History. 36 (2), 185-213.

Ochoa de Eguileor, J. y Valdés, E., 2000. ¿Dónde durmieron nuestros abuelos? Los hoteles de inmigrantes en la ciudad de Buenos Aires. Centro Internacional para la Conservación del Patrimonio, Buenos Aires.
Salvatore, R., 2007. Heights, nutrition and well-being in Argentina, ca. 1850-1950. Preliminary results. Revista de Historia Económica. 25 (1), 53-86

Santilli, D., 2016. ¿Por qué un dossier sobre desigualdad, distribución y nivel de vida en el siglo XIX? Folia Histórica del Nordeste. 26, 64-72.

Santilli, D. y Gelman, J., 2016. Los estudios sobre el nivel de vida. La metodología de la canasta aplicada a la primera mitad del siglo xIx porteño. Folia Histórica del Nordeste. 26, 126-138.

Santos, J. J., 2008. El Tata Dios. Milenarismo y xenofobia en las pampas. Sudamericana, Buenos Aires.

Schmit, R., 2008. Los límites del progreso: expansión rural en los orígenes del capitalismo rioplatense, Entre Ríos 1852-1872. Siglo xxı; Universidad de Belgrano, Buenos Aires.

Schofield, R., 1989. Family structure, demographic behaviour, and economic growt. En: Walter, J. y Schofield, R. (eds.). Famine, disease and the social order in early modern society. Cambridge University Press, Cambridge.

Williamson, J. G., 1995. The evolution of global labor markets since 1830. Background evidence and hypotheses. Explorations in Economic History. 32, 141-196. 